\title{
Four-year survey of medically serious suicide attempters in Abu Dhabi
}

Tarek Shahrour, ${ }^{1}$ Muez Siddiq, ${ }^{1}$ Sona Mohan, ${ }^{1}$ Khadija El Hammasi ${ }^{1}$ and Taoufik Alsaadi ${ }^{2}$

'Department of Psychiatry, Shiekh Khalifa Medical City, Abu Dhabi, United Arab Emirates (Correspondence to: Tarek Shahrour: tshahrour@seha.ae). ${ }^{2}$ American Center for Neurology and Psychiatry, Abu Dhabi, United Arab Emirates.

\begin{abstract}
Background: It is well established that attempting suicide significantly increases a person's risk of completing suicide. The risk is considered to be particularly high in the first year after the attempt. Epidemiological information on suicide is scarce in the Middle East and the countries of the GCC region and there is a need to establish a reference point to measure future changes.
\end{abstract}

Aims: We examined the epidemiology of suicide attempters requiring inpatient care in Abu Dhabi to identify associated factors that could aid local suicide prevention strategies.

Methods: This 4-year (2011-2014) study of suicide attempters in the city of Abu Dhabi included all attempters assessed by the consultation-liaison team and admitted to the 3 main governmental general hospitals.

Results: We identified 364 suicide attempts with an annual incidence of 6 per 100000 population. The mean age was 28.7 years. Females comprised $59.6 \%$ of the attempters and were more likely to be below age 30 years. Around $40 \%$ of the psychiatric diagnoses among attempters were related to stress and $17.9 \%$ to depression. Overdosing was the chosen method in $50.6 \%$ of the attempters, with $32.7 \%$ overdosing on paracetamol and females being more likely to use this method. Just over $13 \%$ of the attempters had made one previous attempt and $2.2 \%$ had made more than one.

Conclusion: Females younger than 30 years were at higher risk of attempting suicide, with overdosing on paracetamol as the preferred method. Stress-related diagnoses were predominant in the attempters.

Keywords: suicide attempts, inpatients, methods, Abu Dhabi

Citation: Shahrour T; Siddiq M; Mohan S; El Hammasi K; Alsaadi T. Four-year survey of medically serious suicide attempters in Abu Dhabi. East Mediterr Health J. 2021;27(3):227-232. https://doi.org/10.26719/emhj.20.099

Received: 14/09/19; accepted: 18/02/20

Copyright (c) World Health Organization (WHO) 2021. Open Access. Some rights reserved. This work is available under the CC BY-NC-SA 3.o IGO license (https://creativecommons.org/licenses/by-nc-sa/3.0/igo).

\section{Introduction}

It is well established that attempting suicide significantly increases the person's risk of completed suicide: prior suicide attempt is the single most important risk factor for suicide (1). A systematic review of 90 studies found the risk to be particularly high in the first year after the attempt as $2 \%$ will end up with completed suicide.

This risk continues to be high even up to 9 years after the indexed attempt (2). Similar figures were found in a follow-up study of suicide attempters in Kuwait where $1.1 \%$ of suicide attempters completed suicide within 2 years (3). Another study in England showed that the risk of a completed suicide in the year following the attempt increased 50 times compared with the risk in the general population (4). Epidemiological information on this phenomenon in the Middle East and the countries of the Gulf Cooperation Council region is scarce and there is a need to establish a reference point to measure changes to this serious phenomenon. There is an argument that this is especially true in the United Arab Emirates, a fast-changing nation in both population and lifestyle aspects. These changes might have an impact on the phenomenon of suicide. Indeed, to our knowledge there have only been 2 studies that reviewed this risk in the Emirate of Dubai $(5,6)$; however, these studies were done on cases of completed suicide and we are not aware of any studies that have addressed the characteristics of suicide attempters in the United Arab Emirates.

\section{Methods}

This was a retrospective survey of medical records that included all patients referred to the consultation-liaison service for a suicide attempt during 2011-2014 inclusive. The referrals came from the medical, surgical, obstetrics/ gynaecology and paediatric inpatient units in the 3 main governmental general hospitals serving greater Abu Dhabi city (Shiekh Khalifa Medical City, Al Mafraq Hospital, and Al Rahba Hospital). These hospitals accept all nationalities in case of emergency, including self-harming attempters. The review team assessed the patients with at least one psychiatric interview. The team used the International Statistical Classification of Diseases (ICD-10) to establish the diagnoses (8), but did not use any structured interview or any other standardized scales in the assessment of patients. The assessment took place in the inpatient setting. The team also recorded the demographic and clinical variables of all patients. All age groups were included, with no exclusion criteria. Critical patients were not excluded as they were eventually assessed once they improved. 
It is worth mentioning that private hospitals are obliged by law to refer all cases of suicide attempt to one of the 3 main governmental general hospitals indicated above. This ensured that all patients needing admission for the treatment of a suicide attempt in greater Abu Dhabi were included in this study.

All screened patients were included in the study and missing data were identified. The study was approved by the ethical and research committee of Sheikh Khalifa Medical City.

Generally, frequencies were estimated in this study. However, the chi-squared test was used for testing relationships between the prevalence of suicide attempts and age and ethnicity. We used SPSS, version 21, for the analysis.

\section{Results}

\section{Demographic and other characteristics}

The age of the attempters ranged between 13 and 77 years, average 28.7 years, with $59.6 \%$ in the $16-30$ years age group. Females were more likely to be in the 16-30 years age group $(P=0.028)$, while Emirati nationals were more likely to be in the $31-65$ years age group $(P=0.02)$. Females comprised $59.6 \%$ of the attempters, with a female to male ratio of 1.5:1.

We found that $34.6 \%$ of the attempters were Emirati nationals, $26.6 \%$ were Arab non-nationals and $25.3 \%$ were from the Indian subcontinent (Table 1). Religion was also noted: $76.1 \%$ of the attempters were Muslim and $5.5 \%$ were Christian.

There was no information on profession for around $20 \%$ of the attempters, however students were strongly represented (Table 1), and, as expected, these students belonged to the 16-30 years age group.

Single people comprised $43.4 \%$ of the attempters, whereas $44.8 \%$ were married (Table 1). No attempters were recorded as being in polygamous marriages.

As mentioned above, $80 \%$ of the Abu Dhabi population consists of non-nationals. Newly arrived migrants are always suspected to be under extra stress. It is, therefore, expected that they should be at higher risk of attempting suicide; however, our study showed that only around $12 \%$ of the suicide attempters were resident in the country for less than 6 months (Table 1), which might not support that hypothesis.

\section{Number of attempts}

The total number of attempts recorded over the 4 years of the study was 364. They were approximately evenly distributed over the 4 years, with an average annual incidence of 6 per 100000 population. There were no significant variations that can be correlated with the month or season of the year.

As the incidence of attempting suicide is generally estimated as 10-20 times the incidence of completed suicide $(9,10)$, the annual incidence of completed suicide

\begin{tabular}{|c|c|c|c|}
\hline Characteristic & No. & $\%$ & $\begin{array}{c}\% \\
\text { of population }\end{array}$ \\
\hline \multicolumn{4}{|l|}{ Ethnicity } \\
\hline National & 126 & 34.6 & 20 \\
\hline Non-national Arab & 97 & 26.6 & 15 \\
\hline Indian subcontinent & 92 & 25.3 & 47 \\
\hline Asian & 15 & 4.1 & 10 \\
\hline African & 24 & 6.6 & 2 \\
\hline Western & 9 & 2.5 & 5 \\
\hline Other & 1 & 0.3 & 3 \\
\hline \multicolumn{4}{|l|}{ Religion } \\
\hline Muslim & 277 & 76.1 & NA \\
\hline Christian & 20 & 5.5 & NA \\
\hline Other & 67 & 12.4 & NA \\
\hline \multicolumn{4}{|l|}{ Education } \\
\hline Illiterate & 6 & 1.6 & \\
\hline 1st to 8 th grade & 46 & 12.6 & \\
\hline 9th to 12 th grade & 100 & 27.5 & \\
\hline Higher & 90 & 24.7 & \\
\hline No information & 122 & 33.5 & \\
\hline \multicolumn{4}{|l|}{ Profession } \\
\hline No information & 74 & 20.3 & \\
\hline Student & 69 & 19.0 & \\
\hline Professional & 61 & 16.8 & \\
\hline Labourer & 58 & 15.9 & \\
\hline Unemployed & 52 & 14.3 & \\
\hline Domestic helper & 36 & 9.9 & \\
\hline Housewife & 9 & 2.5 & \\
\hline Other & 5 & 1.4 & \\
\hline \multicolumn{4}{|l|}{ Marital status } \\
\hline Married & 179 & 44.8 & \\
\hline Single & 158 & 43.4 & \\
\hline Divorced & 21 & 5.8 & \\
\hline Widowed & 6 & 1.6 & \\
\hline \multicolumn{4}{|c|}{$\begin{array}{l}\text { Length of stay in Abu Dhabi } \\
\text { (months) }\end{array}$} \\
\hline $0-1$ & 15 & 4.1 & \\
\hline $2-6$ & 29 & 8.0 & \\
\hline$>6$ & 220 & 60.4 & \\
\hline NA & 100 & 27.5 & \\
\hline
\end{tabular}

NA = data not available

(using our figures) can be estimated to be 0.3 per 100000 population.

\section{Psychiatric diagnosis}

We used the ICD-10 criteria for the diagnosis (8): $40.6 \%$ of the attempters were diagnosed as having either acute stress reaction or adjustment disorder (Table 2), which highlights the strong relationship between stress and 


\begin{tabular}{|c|c|c|}
\hline Psychiatric diagnosis $^{a}$ & No. & $\%$ \\
\hline Adjustment disorder & 78 & 21.4 \\
\hline Acute reaction to stress & 70 & 19.2 \\
\hline Depression & 65 & 17.9 \\
\hline Substance misuse & 36 & 9.9 \\
\hline Accidental overdose & 27 & 7.7 \\
\hline Psychosis & 23 & 6.3 \\
\hline Mania/bipolar affective disorder & 14 & 3.8 \\
\hline Schizophrenia & 6 & 1.6 \\
\hline Other & 38 & 10.4 \\
\hline No information & 6 & 1.6 \\
\hline
\end{tabular}

${ }^{a}$ Diagnosis according to the International Statistical Classification of Diseases (8).

attempting suicide. Depression was diagnosed in $17.9 \%$. Only $9.9 \%$ had history of drug abuse.

\section{Suicide attempt and method used}

Overdosing was the method employed by $50.6 \%$ of the attempters, with $32.7 \%$ having overdosed on paracetamol (Table 3), a method that was more likely among females $(P$ $=0.021)$. Attempters who overdosed on paracetamol were more likely to be aged $16-30$ years $(P=0.002)$. Other commonly used methods were: overdose of other prescribed drugs $(17.9 \%)$, overdose of recreational drugs $(13.2 \%)$ and ingestion of chemicals (11.3\%). Chemical ingestion, especially the ingestion of cleaning materials, was more likely to be used by Asians $(P=0.002)$. Jumping from a height as a suicide method was more likely to be used by attempters in the 31-65 years age group $(P=0.008)$. Overdosing on recreational drugs was more likely to be used by United Arab Emirates nationals $(P=0.008)$.

Leaving a suicide note was found in only $3.3 \%$ of cases, which may be an indicator that the attempt was not quite so serious. All forms of suicide notes were inquired about, including electronic ones (social media, WhatsApp, etc.).

We checked whether the attempt resolved the issue that had precipitated it. Although this was difficult, from the medical notes, we believe that there was a resolution of the precipitating factor (conflict) in $40.9 \%$ of the attempts while there was no resolution in $11.3 \%$. Unfortunately, in $47.8 \%$ of the attempts, we were unable to identify a clear conflict or any precipitating factor, and were unable to check whether either were resolved or not.

We found there had been no previous attempts in $80.5 \%$ of cases; $13.5 \%$ had had one previous attempt and $2.2 \%$ had had multiple attempts. This, as mentioned above, might be in keeping with the fact that a significant proportion of the attempters had stress-related psychiatric diagnoses (Table 2).

\section{Discussion}

Our study provides a good overview of suicide attempters in greater Abu Dhabi, with, however, a major limitation: not including the suicide attempts of those who were discharged directly from the emergency rooms. Nevertheless, in a way, this meant that our study concentrated on the medically/surgically serious attempts. This is one of the explanations for finding a relatively lower incidence for attempted suicide in our study compared with studies from other countries. For example, the annual incidence of attempting suicide in Ireland is 199 per 100000 whereas we found it to be 6 per 100000 (11).

We also noted a significant difference in the estimated annual rate for completed suicide in our study (2-3 per million) when compared with studies in Dubai, which ranged from 5.8 to 6.2 per $100000(5,6)$. This difference may be partially due to the limitation mentioned above; however, it is more likely to be related to the fact that most completed suicides (in the Dubai studies) were carried out by non-nationals of mostly Indian origin and in our study Indians constituted only $25 \%$ of the attempters. This suggests that non-nationals, especially Indians, are likely to die from suicide before coming to the attention of the medical services. Furthermore, nationals are less likely to be given a verdict of suicide for cultural/religious reasons. Most of the attempters were Muslim, but no comparisons can be drawn as no data on the religious breakdown of the population is available to compare with our data.

Another interesting finding was the female to male ratio for attempting suicide of 1.5:1. The ratio of males to females in the general population is 2.5:1, indicating that the likelihood of attempting suicide is nearly 4 greater among females than among males in our population. This finding is in line with Saudi Arabian studies on the pattern of drug overdose (intentional and nonintentional) which showed that females were more likely to attempt suicide $(12,13)$, with a ratio reaching $4: 1$ in one of the studies (12). This is also in keeping with the statistics on attempted suicide from other countries, where it has been established to be higher in females (14). Conversely, studies on completed suicide in Dubai $(5,6)$ showed much higher number of suicides in males, with a ratio of 4:1. The question remains whether men are less likely to reach the attention of the medical services before dying from suicide.

Table 3 Method used among suicide attempters $(n=364)$ in Abu Dhabi, 2011-2014

\begin{tabular}{lcc} 
Suicide method & No. & $\%$ \\
\hline Paracetamol overdose & 119 & 32.7 \\
Overdose of other prescribed medication & 65 & 17.9 \\
Recreational drug overdose & 48 & 13.2 \\
Chemical ingestion & 41 & 11.3 \\
Violent method (stabbing, burning, hanging) & 35 & 9.6 \\
Jumping from height & 22 & 6.0 \\
Wrist cutting & 11 & 3.0 \\
Other & 22 & 6.0 \\
\hline
\end{tabular}


We found that the number of people attempting suicide seems to be greater among those who had better education compared with those who had less education, which might suggest that the latter group may have had poorer access to medical services.

The average age of 28.7 years in our study matches the findings in other studies (14). Suicide seems to be high in this age group worldwide; it is the second leading cause of death in the United States of America in the age group 15-34 years (15). A study on completed suicide in Dubai showed similar higher numbers for completed suicide in the under 30 years age group (5), but a later study showed less clear results on this (6). We found that the Emirati nationals in our study were more likely to be in an older age group, possibly due to the fact that they are the stable population: other nationalities have a higher turnover and tend to repatriate and leave the country at a relatively younger age.

Rates were nearly equal for married and single suicide attempters; divorced and widowed attempters were minorities in our study, although we could not draw firm conclusions from the numbers due to lack of information on marital status in the general population. From previous research, we would have expected the number of married attempters to be lower $(16,17)$. Polygamy was suggested to be a risk factor for overdosing in a Saudi study (12) but none of the people included in our study were in a polygamous marriage.

The incidence of leaving a suicide note in our study was quite low, but this was nearly the same as that in a study done on completed suicide in Dubai (5). It was also in keeping with a study done in London, which, over the course of 5 years, found that only $15 \%$ of suicide attempters had left a note. Moreover, the researchers gained no extra insight from reviewing the content of the notes (18).

Comparison between our study and other published studies is limited due to not including emergency room suicide attempters, as mentioned above; however, one study looked only at serious suicide attempts and we can compare its results with ours. That study showed a similar proportion of attempts using self-poisoning $(78 \%)$ to our own finding of $70 \%$ in total (counting prescribed medication, paracetamol, chemical ingestion, and recreational drugs) (19). The population in that study had a similar mean age to our study, 30 years, but had a male to female ratio of nearly 1:1.

The other issue that we need to highlight is the method used for suicide. A recent large meta-analysis clearly showed strong evidence of significant suicide prevention when restricting the lethal means (20). This evidence was particularly clear for the restrictions on analgesics. The WHO report on the prevention of suicide also places great emphasis on restricting access to the method of suicide (1). Our study has shown that the use of analgesics, especially paracetamol, in overdosing was the most common method in serious suicide attempts. Our results are similar to the 2 Saudi Arabian studies on overdosing, which showed that NSAIDs were overrepresented, with one of the studies showing paracetamol to constitute $30 \%$ of the drugs used $(12,13)$.

Limiting our population of suicide attempters to admitted patients only, we accept that it will be difficult to base any policy change, such as the restriction of analgesics, on the conclusions of this study. However, the study on completed suicide in Dubai found self-poisoning to be one of the most likely methods to be used, especially females (5). Similarly, an Iranian study on adolescents has shown that overdosing was the main mean of suicide, which would further suggest the benefit of such restriction measures (21). Furthermore, we believe there is a case for devising and implementing an educational programme in schools, targeting females particularly, as evidence also confirms the benefits of such a prevention method (20).

Treatment of affective disorders may be beneficial in our population as there is a clear evidence for prevention of suicide by treating depression, especially reflecting on the significant proportion of the attempters in our study with a diagnosis of depression (20). Having said that, the biggest share of suicide attempters had stressrelated disorders. Two Indian studies showed similar findings, with adjustment disorder being the number one psychiatric diagnosis in patients who attempted suicide $(22,23)$. This differs from a Scandinavian cohort study, which showed severe psychiatric disorders to be the most likely diagnosis that led to completed suicide (24). This poses the question of whether the effect of the diagnosis on the risk of suicide is a universal phenomenon or a culturally bound risk factor. Furthermore, it emphasizes the importance of the relationship between stress and suicide and may again put further emphasis on the restriction of the means of suicide and on education rather than the treatment approach to prevention.

Funding: Funding was provided from Sheikh Khalifa Medical City.

Competing interests: None declared. 


\section{Enquête de quatre ans sur les personnes ayant fait des tentatives de suicide médicalement graves à Abu Dhabi}

\section{Résumé}

Contexte : Il est un fait bien établi que toute tentative de suicide antérieure augmente considérablement le risque pour une personne de réitérer cet acte. Ce risque est considéré comme particulièrement élevé au cours de la première année suivant la tentative. Les informations épidémiologiques sur le suicide sont rares au Moyen-Orient et dans les pays du Conseil de Coopération du Golfe. Il est nécessaire d'établir un point de référence pour mesurer les changements futurs.

Objectifs : Nous avons examiné l'épidémiologie des personnes ayant tenté de se suicider qui nécessitaient des soins hospitaliers à Abu Dhabi afin d'identifier les facteurs associés qui pourraient être utiles aux stratégies locales en matière de prévention du suicide.

Méthodes : La présente étude de quatre ans (2011-2014) menée dans la ville d'Abu Dhabi a couvert l'ensemble des personnes ayant tenté de se suicider, évaluées par l'équipe de liaison pour la consultation et admises dans les trois principaux hôpitaux généraux publics.

Résultats: Nous avons identifié 364 tentatives de suicide correspondant à une incidence annuelle de six pour 100000 habitants. Lâge moyen était de 28,7 ans. Les femmes représentaient 59,6\% des personnes ayant fait une tentative de suicide et étaient davantage susceptibles d'avoir moins de 30 ans. Environ $40 \%$ des diagnostics psychiatriques chez ces dernières étaient liés au stress et $17,9 \%$ à la dépression. Le surdosage a été la méthode choisie chez 50,6\% des personnes qui ont fait une tentative de suicide, avec 32,7\% d'overdose de paracétamol, les femmes étant plus susceptibles d'utiliser cette méthode. Un peu plus de $13 \%$ des personnes ayant fait une tentative de suicide étaient récidivistes et 2,2\% étaient multirécidivistes.

Conclusion : Les femmes de moins de 30 ans étaient plus exposées au risque de tentative de suicide, le paracétamol étant la méthode privilégiée pour le surdosage. Les diagnostics liés au stress étaient prédominants chez les personnes ayant fait une tentative de suicide.

$$
\text { مالتهح مدته أربع سنوات في أبو ظبي عن الأشخاص الذين شرعوا في الانتحار وتطلبو ارعاية طبية نظر اً لخطورة }
$$

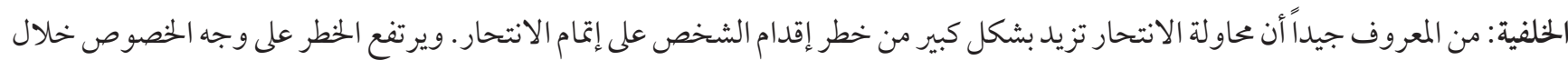

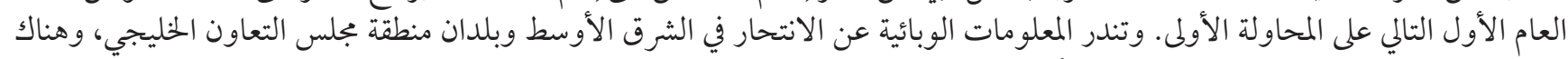

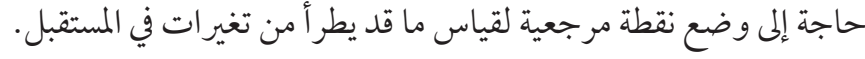

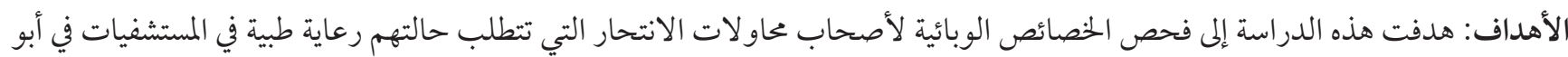

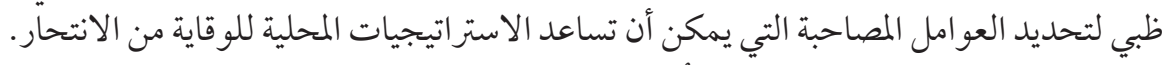

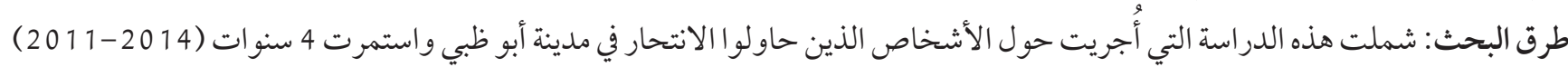

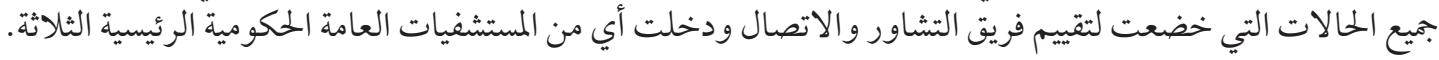

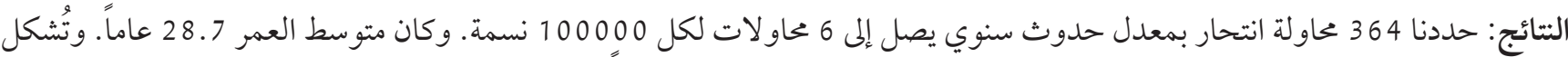

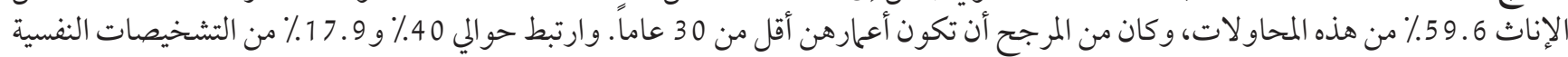

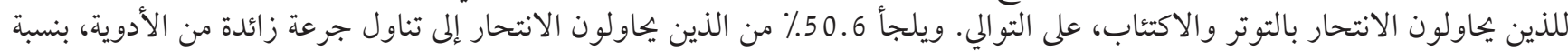

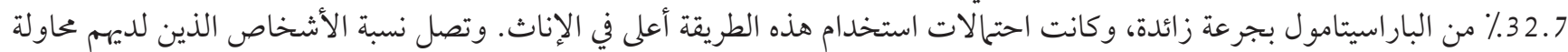

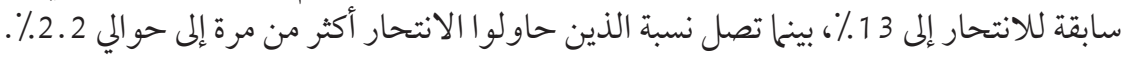

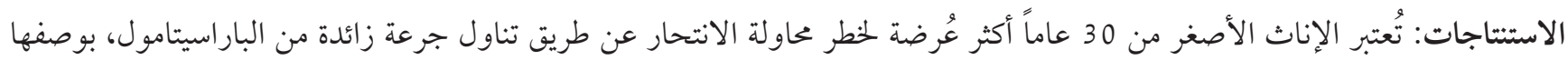

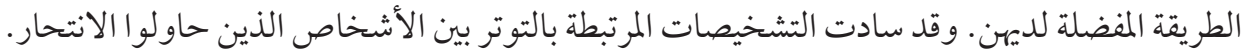




\section{References}

1. Preventing suicide: a global imperative. Geneva: World Health Organization; 2014.

2. $\quad$ Owens D, Horrocks J, House A. Fatal and non-fatal repetition of self-harm. Systematic review. Brit J Psychiatry. 2002;181(3):19399. doi:10.1192/bjp.181.3.193

3. Suleiman MA, Moussa MA, el-Islam MF. The profile of para suicide repeaters in Kuwait. Int J Soc psychiatry. 1989 summer;35(2):146-55. doi:10.1177/002076408903500202

4. Hawton K, Bergen H, Cooper J, Turnbull P, Waters K, Ness J, et al. Suicide following self-harm: findings from the multicenter study of self-harm in England, 2000-2012. J Affect Disord. 2015;175:147-51. doi:10.1016/j.jad.2014.12.062

5. Koronfel, A. A.. Suicide in Dubai, United Arab Emirates. J Clin Forensic Med. 2002;9(1):5-11. doi:10.1054/jcfm.2002.0514

6. Dervic K, Amiri L, Niederkrotenthaler T, Yousef S, Salem M, Voracek M, et al. Suicide rates in the national and expatriate population in Dubai, United Arab Emirates. Int J Soc Psychiatry. 2012 Nov;58(6):652-6. doi:10.1177/0020764011430038

7. Statistical yearbook of Abu Dhabi 2012. Abu Dhabi: Statistics Center; 2014.

8. International Statistical Classification of Diseases, 10th rev (ICD-10). Geneva: World Health Organization; 1994.

9. Figures and facts about suicide. Geneva: World Health Organization; 1999 https://apps.who.int/iris/handle/10665/66097, accessed 5 July 2020).

10. Persett PS, Grimholt TK, Ekeberg O, Jacobsen D, Myhren H. Patients admitted to hospital after suicide attempt with violent methods compared to patients with deliberate self-poisoning -a study of background variables, somatic and psychiatric health and suicidal behavior. BMC Psychiatry. 2018;24:18(1):21. doi:10.1186/s12888-018-1602-5

11. Griffin E, Arensman E, Corcoran P, Wall A, Williamson E, Perry I. National self-harm registry ireland annual report 2014. Cork, Ireland: National Suicide Research Foundation. 2015.

12. Al-Jahdali H, Al-Johani A, Al-Hakawi A, Arabi Y, Ahmed QA, Altowirky J, et al. Pattern and risk factors for intentional drug overdose in Saudi Arabia. Can J Psychiatry. 2004;49(5):331-4. doi:10.1177/070674370404900509

13. Bakhaidar M, Jan S, Farahat F, Alsaywid B, Abuznadah W. Pattern of drug overdose and chemical poisoning among patients attending an emergency department, Western Saudi Arabia. J Community Health. 2015;40(1):57-61. doi:10.1007/s10900-014-9895-x

14. Corcoran P, Keeley HS, O'Sullivan M, Perry IJ. The incidence and repetition of attempted suicide. Eur J Public Health. Mar 2004;14(1):19-23. doi:10.1093/eurpub/14.1.19

15. Web-based injury statistics query and reporting system (WISQARS). Atlanta: Centers for Disease Control and Prevention, National Center for Injury Prevention and Control; 2013.

16. Kim JW, Jung HY, Won DY, Noh JH, Shin YS, Kang TI. suicide trends according to age, gender, and marital status in South Korea. Omega (Westport). 2019 May;79(1):90-105. doi:10.1177/0030222817715756

17. Griffiths C, Ladva G, Brock A, Baker A. Trends in suicide by marital status in England and Wales, 1982-2005. Health Stat Q. 2008;(37):8-14. PMID:18351023

18. O’Donnell I, Farmer R, Catalan J. Suicide notes. Br J Psychiatry. 1993;163:45-8. doi:10.1192/bjp.163.1.45

19. Beautrais AL. Subsequent mortality in medically serious attempts: a 5 year follow up. Aust NZ J Psychiatry. 2003 Oct;37(5):595-9. doi:10.1046/j.1440-1614.2003.01236.x

20. Zalsman G, Hawton K, Wasserman D, van Heeringen K, Arensman E, Sarchiapone M, et al. Suicide prevention strategies revisited: 10-year systematic review. Lancet Psychiatry. 2016;3(7):646-59. doi:10.1016/S2215-0366(16)30030-X

21. Mokhatari AM, Salari A, Hassanipour S, Mirahamadizadeh A. Epidemiology of suicide in 10-19 years old in southern Iran, 2011-2016: a population-based study on 6720 cases. J Forensic Leg Med. 2019 Aug; 66:129-133. doi:10.1016/j.jflm.2019. 06.018.

22. Galgali.R.B, Sanjeev Rao, Ashok.M.V, Appaya.P and Srinivasan.K, Psychiatric diagnosis of self poisoning cases a general hospital study. Indian J Psychiatry. 1998;40(3):254-9. PMID:21494481

23. Baby S, Haridas M, Yesudas KF. Psychiatric diagnosis in attempted suicide. Calicut Med J. 2006;4(3):e2.

24. Tidemalm D, Långström N, Lichtenstein P, Runeson B. Risk of suicide after suicide attempt according to coexisting psychiatric disorder: Swedish cohort study with long-term follow-up. BMJ. 2008;337:a2205. doi:10.1136/bmj.a2205 